\title{
Comparative Study of End Moments Regarding Application of Rotation Contribution Method (Kani's Method) \& Moment Distribution Method for the Analysis of Portal Frame
}

\author{
P. R. Patil, M. D. Pidurkar, R. H. Mohankar \\ Asst. Professor-Priyadarshini J. L. College of Engineering, Nagpur, Maharashtra (India)
}

\begin{abstract}
Analysis of portal frames involves lot of complications and tedious calculations by conventional methods. To carry out such analysis is a time consuming task. The rotation contribution method i.e. Kani's Method \& Moment Distribution Method for analysis of portal frames can be handy in approximate and quick analysis so as to get the detailed estimates ready. In this work, these two methods have been applied only for vertical loading conditions. This paper presents the analysis of portal frame, considering mainly the case of single bay portal frame, which is the most common in practice. The Kani's method is self correcting, that is, the error, if any, in a cycle is corrected automatically in the subsequent cycles. The checking is easier as only the last cycle is required to be checked. The convergence is generally fast. It leads to the solutions in just a few cycles of iterations.
\end{abstract}

Keywords - Portal Frame, Kani's Method, Moment Distribution Method, Rotation Contribution Method

\section{Introduction}

For the design of portal frames, Kani's method and moment distribution methods of analysis are mainly used, which allows the engineer to analyze frames easily and design it economically. The research is concluded by evaluating a selection of portal frame, with practical dimensions in order to substantiate the conclusions as stated below.

Portal Frames: Portal frames are single storey, single or multi-bay frames with pitched or flat roof (Figure 1). The vertical and top members are rigidly joined. The frames may be fixed or hinged at the base. A simple portal frame consists of a horizontal beam resting on two columns. The junction of the beam with the column consists of rigid joints. If the loading is symmetrical, there will be no joint translation or sway.

This paper presents the analysis of portal frame, considering mainly the case of single bay, which is the most common in practice.

Portal frames are very efficient and economical when used for single-storey buildings, provided that the design details are cost effective and the design parameters and assumptions are well chosen. In countries where this technology is highly developed, the steel portal frame is the dominant form of structure for singlestorey industrial and commercial buildings. It has become the most common structural form in pitched roof buildings, because of its economy and versatility for a wide range of spans.

\subsection{Structure}

\section{HISTORY}

In engineering and architecture, A structure is the assemblage of two or more basic structural components connected together in such a way that they serve the user functionally and carry the loads arising out of self and super-imposed loads safely without causing any problem of serviceability.

Physical structures include man-made and natural arrangements. Buildings, aircrafts, bridges, culverts, water tanks, skeletons, dams and domes are all examples of physical structures. The effects of loads on physical structures are determined through structural analysis. Structural engineering refers to engineering of physical structures.

\subsection{Structural Analysis}

Structural analysis deals with study and determination of forces in various components of a structure subjected to loads. As the structural system as a whole and the loads acting on it may be of complex nature certain simplifying assumptions with regard to the quality of material, geometry of the members, nature and distribution of loads and the extent of connectivity at the joints and the supports are always made to make the analysis simpler. 


\subsection{Kani's Method:}

This method was introduced by Gasper Kani's in 1947. It involves distributing the unknown fixed end moments of structural members to adjacent joints, in order to satisfy the conditions of continuity of slopes and displacements.

\subsection{Moment Distribution Method:}

This method was first introduced by Prof. Hardy Cross is widely used for the analysis of intermediate structures. In this method first the structural system is reduced to its kinematically determinate form, this is accomplished by assuming all the joints to be fully restrained. The fixed end moments are calculated for this condition of structure. The joints are allowed to deflect rotate one after the other by releasing them successively. The unbalanced moment at the joint shared by the members connected at the joint when it is released.

\section{Methodology Adopted}

This paper presents the analysis of portal frame, considering mainly the case of single bay, which is the most common in practice, by using two most common methods viz. moment distribution method \& rotation contribution method (Kani's method). The vertical and top members are rigidly joined. The frame is fixed at one end and hinged at other end at the base. The portal frame consists of a horizontal beam resting on two columns.

For all beams, $\mathrm{I}=>2 \mathrm{I}$

For all columns, I => I

The junction of the beam with the column consists of rigid joints. (Figure 1)

Figure1. Portal Frame considered for the analysis

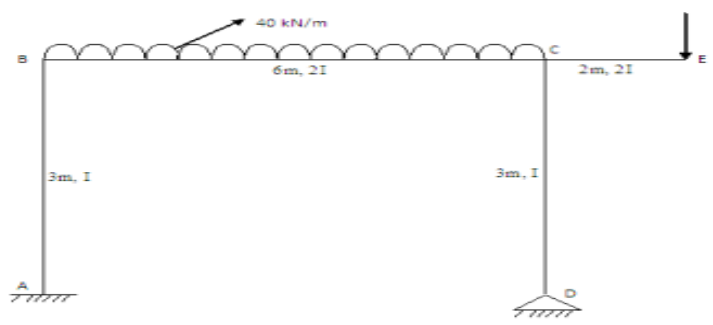

A] Analysis by Kani's Method:

Framed structures are rarely symmetric and subjected to side sway, hence Kani's method is best and much simpler than other methods.

PROCEDURE:

1. Rotation stiffness at each end of all members of a structure is determined depending upon the end conditions.

a. Both ends fixed

$\mathrm{Kij}=\mathrm{Kji}=\mathrm{EI} / \mathrm{L}$

b. Near end fixed, far end simply supported

$\mathrm{Kij}=3 / 4 \mathrm{EI} / \mathrm{L} ; \mathrm{Kji}=0$

2. Rotational factors are computed for all the members at each joint it is given by

$$
\mathrm{Uij}=-0.5(\mathrm{Kij} / \text { ?Kii) }
$$

\{THE SUM OF ROTATIONAL FACTORS AT A JOINT IS -0.5\}

(Fixed end moments including transitional moments, moment releases and carry over moments are computed for members and entered. The sum of the FEM at a joint is entered in the central square drawn at the joint).

3. Iterations can be commenced at any joint however the iterations commence from the left end of the structure generally given by the equation

$$
\text { M?ij = Uij [(Mfi + M??i) + ? M?ji)] }
$$

4. Initially the rotational components? Mji (sum of the rotational moments at the far ends of the joint) can be assumed to be zero. Further iterations take into account the rotational moments of the previous joints.

5. Rotational moments are computed at each joint successively till all the joints are processed. This process completes one cycle of iteration.

6. Steps 4 and 5 are repeated till the difference in the values of rotation moments from successive cycles is neglected.

7. Final moments in the members at each joint are computed from the rotational members of the final iterations step.

$$
M i j=(M f i j+M ? ? i j)+2 M ? i j+M ? j i i
$$


The lateral translation of joints (side sway) is taken into consideration by including column shear in the iterative procedure.

8. Displacement factors are calculated for each storey given by

$$
\mathrm{Uij}=-1.5(\mathrm{Kij} / ? \mathrm{Kij})
$$

B] Analysis by Moment Distribution method:

This is also known as Hardy cross method. It provides a convenient means of analyzing statically determinate structures (beams and frames) by manual calculations. This is basically an iterative process. It involves artificially restraining temporarily all the joints against rotations and writing down the fixed end moments for all the members. The joints are then released one by one in succession. At each released member joint the unbalanced moments are distributed to all the ends of the members meeting at that joint. Certain factors of these distributed moments are carried over to the far end of members. The released joint is again restrained temporarily before proceeding to the next joint. The same sets of operations are carried out at each joint till all the joints are completed. This completes one cycle of operations. The process is repeated for a number of cycles till the values obtained are within the desired accuracy. This method is also a displacement analysis. But this method does not involve solving simultaneous equations as in case of slope deflection method. This method is very popular as it is free from solving simultaneous equations if the frames do not undergo lateral deformations.

\section{Application Of Analysis Methods For The Portal Frame}

\subsection{Application of Rotation contribution Method (Kani's Method) for the analysis of portal frame:}

\subsubsection{Fixed end moments}

$$
\begin{aligned}
& \mathrm{FEM}_{\mathrm{AB}}=0 \\
& \mathrm{FEM}_{\mathrm{BA}}=0 \\
& \mathrm{FEM}_{\mathrm{BC}}=-120 \mathrm{kNm} \\
& \mathrm{FEM}_{\mathrm{CB}}=120 \mathrm{kNm} \\
& \mathrm{FEM}_{\mathrm{CD}}=0 \\
& \mathrm{FEM}_{\mathrm{DC}}=0
\end{aligned}
$$

\begin{tabular}{|c|c|c|c|c|}
\hline Joint & Member & K & $\Sigma \mathrm{K}$ & RF \\
\hline \multirow[t]{2}{*}{ B } & BA & $0.333 \mathrm{I}$ & \multirow[t]{2}{*}{$0.666 \mathrm{I}$} & -0.25 \\
\hline & BC & $0.333 \mathrm{I}$ & & -0.25 \\
\hline \multirow[t]{2}{*}{ C } & CB & $0.333 \mathrm{I}$ & \multirow[t]{2}{*}{$0.583 \mathrm{I}$} & -0.286 \\
\hline & CD & $0.25 \mathrm{I}$ & & -0.214 \\
\hline
\end{tabular}

\subsubsection{Stiffness and rotation factor (R.F.)}

Table 1. Stiffness and Rotation Factors - Kani's Method

\subsubsection{Displacement factors $(\delta)$}

Table 2. Calculation of Displacement factors $(\delta)$

$\Sigma \mathrm{UCD}=(-1.2)+(-0.3)=-1.5$ Checked. Hence OK

\subsubsection{Storey Moment (SM)}

Storey moment $=0$

(since lack of nodal loads and lack of loadings on columns, $\mathrm{SM}=0$ )

\subsubsection{Iterations by Kani's Method}

Figure 2. Calculations of rotation contributions in tabular form using Kani's Method

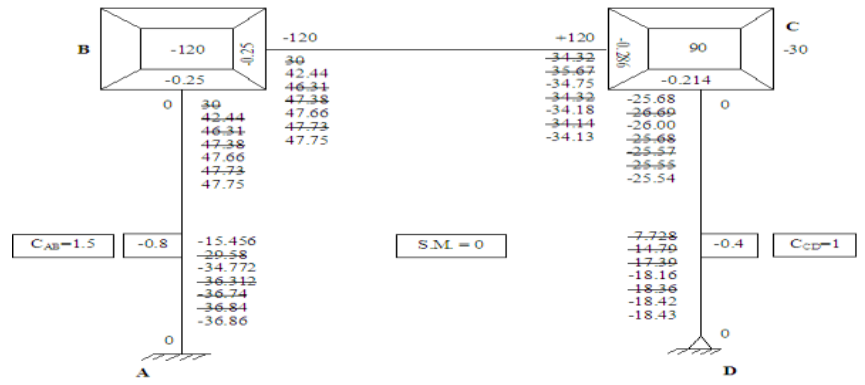




\subsubsection{Final End Moments}

For columns: => F.E.M +2 (near end contribution $)+$ far end contribution of that particular column + L.D.C. of that column

For beams: => F.E.M + 2 (near end contribution) + far end contribution of that particular beam or slab.

$$
\begin{aligned}
& \mathrm{M}_{\mathrm{AB}}=10.89 \mathrm{kNm} \\
& \mathrm{M}_{\mathrm{BA}}=58.64 \mathrm{kNm} \\
& \mathrm{M}_{\mathrm{BC}}=-58.63 \mathrm{kNm} \\
& \mathrm{M}_{\mathrm{CB}}=99.49 \mathrm{kNm} \\
& \mathrm{M}_{\mathrm{CD}}=-69.51 \mathrm{kNm} \\
& \mathrm{M}_{\mathrm{DC}}=0 \mathrm{kNm} \\
& \mathrm{M}_{\mathrm{CE}}=-30 \mathrm{kNm}
\end{aligned}
$$

4.2. Application of Moment distribution Method (Hardy Cross Method) for the analysis of portal frame: 4.2.1. Fixed end moments will be same as 4.1.1

\begin{tabular}{|c|c|c|c|c|c|c|c|}
\hline \multirow{2}{*}{$\begin{array}{l}\text { Node / Joint } \\
\text { Distribution } \\
\text { Fow }\end{array}$} & & \multicolumn{2}{|c|}{ B } & \multicolumn{3}{|c|}{ c } & \\
\hline & & 03 & 0.5 & 0.57 & 0 & 0.43 & \\
\hline Nambet & $A B$ & $B A$ & $B C$ & $\mathrm{CB}$ & $\mathrm{CE}$ & $\mathbb{C D}$ & $D C$ \\
\hline \multirow{11}{*}{ FEM } & 0 & 0 & .120 & 120 & -30 & 0 & 0 \\
\hline & & 60 & $60=$ & / 51.3 & 1 & .38 .7 & 1 \\
\hline & 30 & & $-25,65$ & 230 & & & \\
\hline & & 12.825 & 12.825 & $<-17.1$ & & -129 & \\
\hline & 6.4125 & & -8.55 & 6.4125 & & & \\
\hline & & & 4.275 & $<^{-3.655}$ & & .2 .7574 & \\
\hline & 2.1375 & & $.1 \$ 273$ & 2.1375 & & & \\
\hline & & 0.914 & 0.914 & $e^{-1.2184}$ & & 09191 & \\
\hline & 0.4569 & & 0.6092 & 0.4569 & & & \\
\hline & & 0.3046 & 0.3046 & 0.2604 & & 0.1964 & \\
\hline & 0.1523 & & 0.1302 & 0.1523 & $\downarrow$ & & $\downarrow$ \\
\hline Final Moment & 38.85 & 73.383 & -78.38 & 85.53 & -30 & -53.55 & 0 \\
\hline
\end{tabular}

\subsubsection{Stiffness and distribution factor}

Table 3. Stiffness and Distribution Factors - Moment Distribution Method

\begin{tabular}{|c|c|l|l|l|}
\hline Joint & Member & $\mathrm{K}$ & $\Sigma \mathrm{K}$ & $\mathrm{DF}$ \\
\hline $\mathrm{B}$ & $\mathrm{BA}$ & $0.333 \mathrm{I}$ & \multirow{2}{*}{$0.666 \mathrm{I}$} & 0.5 \\
\cline { 2 - 3 } & $\mathrm{BC}$ & $0.333 \mathrm{I}$ & \multirow{2}{*}{$0.583 \mathrm{I}$} & 0.57 \\
\hline \multirow{2}{*}{$\mathrm{C}$} & $\mathrm{CB}$ & $0.333 \mathrm{I}$ & \multirow{2}{*}{0.583} \\
\cline { 2 - 3 } & $\mathrm{CD}$ & $0.25 \mathrm{I}$ & & 0.43 \\
\hline
\end{tabular}

\subsubsection{Non-Sway Moment Distribution}

The non-sway moments has been calculated according to moment distribution method as per table 4 . Table 4: Non-Sway Moment Distribution using Moment Distribution Method

\subsubsection{Sway moment distribution}

Sway moment distribution has been determined in table 5, by assuming the portal frame sways towards right as in figure 3. Also the value of 6EI $\Delta$ has been assumed as 100 .

Figure 3: Right direction Sway of portal Frame

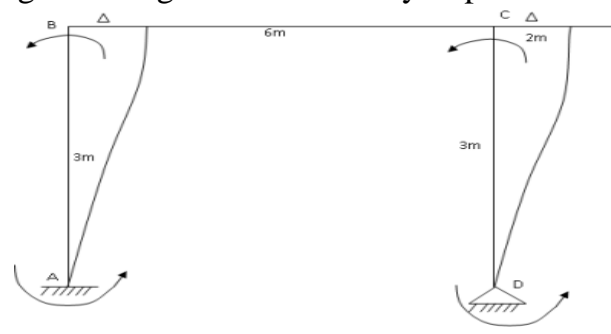

Table 5: Sway Moment Distribution using Moment Distribution Method 


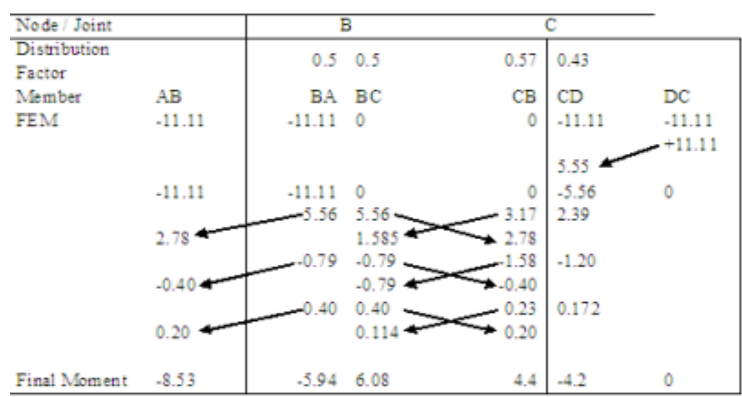

\subsubsection{Calculation of Sway-Correction Factor $(\mathbf{K})$}

The numerical value of sway correction factor, $\mathrm{K}$ has been obtained as 3.3, which is taken into consideration while calculating final End Moments

Figure 4 (a), (b): Sway and Non-Sway Moment distribution, for the calculation of sway correction factor-K.

K

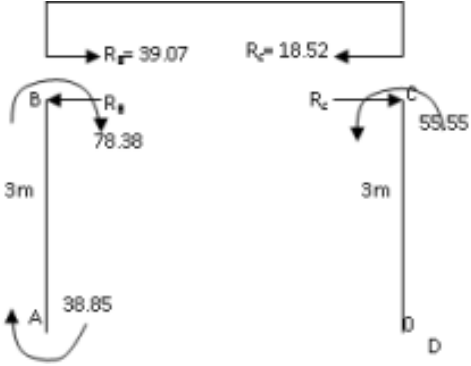

(a)

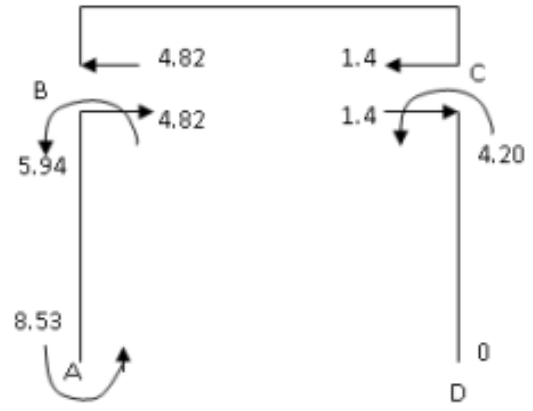

(b)

\subsubsection{Final End Moments}

The final end moments have been calculated as the respective addition of Sway moments $+\mathrm{K}$ times NonSway Moments.

$$
\begin{aligned}
& \mathrm{M}_{\mathrm{AB}}=10.70 \mathrm{kNm} \\
& \mathrm{M}_{\mathrm{BA}}=58.78 \mathrm{kNm} \\
& \mathrm{M}_{\mathrm{BC}}=-58.32 \mathrm{kNm} \\
& \mathrm{M}_{\mathrm{CB}}=100.07 \mathrm{kNm} \\
& \mathrm{M}_{\mathrm{CD}}=-69.41 \mathrm{kNm} \\
& \mathrm{M}_{\mathrm{DC}}=0 \mathrm{kNm} \\
& \mathrm{M}_{\mathrm{CE}}=-30 \mathrm{kNm}
\end{aligned}
$$

\section{Investigative Analysis}

After the analysis is completed, the results of the end moments of the portal frame considered has been compared and an investigative analysis is done.

\subsection{Comparative Study Of End Moments}

\begin{tabular}{|c|c|c|c|}
\hline & \multicolumn{2}{|c|}{ End Moments (kN.m) } & \multirow{2}{*}{$\begin{array}{c}\% \\
\text { Variations }\end{array}$} \\
\cline { 2 - 3 } & Kani's Method & $\begin{array}{c}\text { Moment Distribution } \\
\text { Method }\end{array}$ & $1.74 \%$ \\
\hline $\mathrm{M}_{\mathrm{AB}}$ & 10.89 & 10.70 & $0.24 \%$ \\
\hline $\mathrm{M}_{\mathrm{BA}}$ & 58.64 & 58.78 & $0.53 \%$ \\
\hline $\mathrm{M}_{\mathrm{BC}}$ & -58.63 & -58.32 & $0.58 \%$ \\
\hline $\mathrm{M}_{\mathrm{CB}}$ & 99.49 & 100.07 & $0.14 \%$ \\
\hline $\mathrm{M}_{\mathrm{CD}}$ & -69.51 & -69.41 & $0 \%$ \\
\hline $\mathrm{M}_{\mathrm{DC}}$ & 0 & 0 & $0 \%$ \\
\hline $\mathrm{M}_{\mathrm{CE}}$ & -30 & -30 & \\
\hline
\end{tabular}




\section{CONCLUSIONS AND RECOMMENDATIONS}

1. The End Moments calculated by the application of rotation contribution method, i.e. Kani's Method, for the analysis of considered portal frame, mostly matches with those calculated by the application of Moment Distribution method.

2. The percentage variation of End Moments is within acceptable limit.

3. The percent variation can be further reduced with the increase in number of iterations in both analysis methods.

4. It is found that, only 3-4 iteration are sufficient while using Kani's Method; which is somewhat less as compared with Moment Distribution Method.

5. The Kani's method is self correcting, that is, the error, if any, in a cycle is corrected automatically in the subsequent cycles. The checking is easier as only the last cycle is required to be checked.

6. The convergence is generally fast. It leads to the solutions in just a few cycles of iterations.

7. After the analysis, frame under consideration is statically determinate and contains all end moments. It can be designed now for detailed estimate.

\section{REFERENCES}

[1] Junnarkar S.B. Mechanics of Structures, Valumes I \& II. Chartor Book Stall, Anand, India.

[2] Mohan Kalani. Analysis of continuous beams and frames with bars of variable crosssection. I. Indian Concrete Journal, March 1971

[3] Raz Sarwar Alam. Analytical Methods in Structural Engineering. Wiley Eastern Private Limited, New Delhi, India.

[4] Vazirani V.N. \& Ratwani M.M. Analysis of Structures, Khanna Publishers, Delhi, India.

[5] Volokh, K.Y. (2002). On foundations of the Hardy Cross method. International Journal of Solids and Structures, Volume 39, Issue 16, August 2002, Pages 4197-4200 